Page 105-118. ISBN: 978-602-6 988-75-1

Web Jurnal Online: jurnal.unmuhjember.ac.id

By: Festa Yumpi Rahmanawati

Building Family Resilience: A Case Study In A Muslim Family With Autism Child

\title{
BUILDING FAMILY RESILIENCE: A CASE STUDY IN A MUSLIM FAMILY WITH AUTISM CHILD
}

\author{
Festa Yumpi Rahmanawati \\ festayumpi@unmuhjember.ac.id \\ Fakultas Psikologi Universitas Muhammadiyah Jember, Indonesia
}

\begin{abstract}
Crisis and challenge are inherent in the human condition. Families of children with autism spectrum disorders (ASD) experience significant stress event. Families are broadly viewed as a deficient, high risk in which families are susceptible to multiple problems. The mechanism of strength and vulnerability in these families are poorly understood. This study explores how the family of the child with ASD build resilience that was provided from the Muslim family point of view of a child with ASD in using Islamic values. Using the case study method, one family of a child with ASD discuss meaningful insights into how Islamic values support their way to be resilient. The findings of this study can help Muslim families better understand the resilience which contributes to positive parenting for their special need children. Four themes emerged: a) wonderful purpose behind adversity and stress; b) gratitude to small successes; c) having a support system for powerful energy; d) focusing on the hereafter The implication of these findings also can enhance the ability to manage effectively in parenting stress that was faced family of children with ASD.
\end{abstract}

Keyword: family resilience, Muslim family, the family with autism child, case study 


\section{INTRODUCTION}

Family with autism spectrum disorders (ASD) often report high levels of stress and mental health problems. Parents of children with ASD report greater emotional problems compared to parents of typically developing children (Hayes \& Watson, 2013)Because of the severity of the disorder, many families struggle to come to terms with their child's diagnosis and to adjust to having a child with special needs in their home.Parents usually have the major obligation of caring for their child which includes management of problematic behaviors and balancing associated stress. Family was concerned the ability to rise from crisis and to adapt in living daily life. The concept of family resilience is the ability of a family to respond positively to an adverse event and emerge strengthened, more resourceful and more confident(Walsh, 2012b). Despite the challenges faced by the families of autistic children, some families are able to cope remarkably well, while others have considerable difficulty in dealing with these challenges(Yumpi-R, 2016). How does the resilience emerge in a family with autism child. Little research exists specifically on the context of resilience the family with ASD.

Walsh (2012a)suggested the spiritual dimension contribute to family resilience. Study about Islamic value reported the importance of these values.For example, study on Bensaid, Machouche, \& Grine (2014)concludes that spiritual intelligence developed in accordance with a Qur'anic framework that incorporates spiritual consciousness into a system of belief, worship, morality and social responsibility. Zanariah \& Shah (2015) showed that Islamic spiritual intelligence can lead us to appreciate more the greatness of Allah and help us to fulfill our role as the khalifah (vicegerent of Allah).There are lack of explanation of the dynamic how Islamic value support the family resilience. This study explore how Islamic value contribute to resilience of family with autism child.

\section{THE CONCEPT OF FAMILY RESILIENCE}

The concept of family resilience extends our understanding of family functioning to situations of adversity. Family resilience is the concept that lie in the original study of individual resilience. Beyond seeing individual family members as potential resources for individual resilience, the concept of family resilience focuses on risk and resilience in the family as a functional unit. This theory builds on a competence-based and strength-oriented family paradigm that allows a greater understanding of how families display resilience when challenged by adversity(Walsh, 2012a). According to Walsh, to gain understanding of how families display resilience when faced with adversity was built from competence-based and strength-oriented family paradigm (Sixbey, 2005)

Research literature on family resilience shows the family level in operating family function that focused on adapting of family members under adversity - including strong emotional bonds,effective patterns of communication, the use of coping strategies and familybelief systems, especially those based on spiritual or religious values. The ability recover from adversity stronger and more resourceful is the concept family resilience. Risk factors and protective factors are the concepts that relates to family resilience concept. Risk factors bring consequence to the probability of negative outcomes. Protective factorsinteract with risk to change the predictive relationship between risk factors and negative outcomes, reducing the probability of negative outcomes. 
Vulnerability also the concept used by researchers, has been subject to family resilience concept.Vulnerabilityfactors increase the probability of negative outcomes in the presence of risk.According to (Walsh, 2012a) "the family resilience framework serves as a conceptual map to identify and target key family processes that can reduce stress and vulnerability in high-risk situations, foster healing and growth out of crisis, and empower families to overcome prolonged adversity".

\section{FAMILY WITH AUTISM CHILD}

The American Psychiatric Association's (APA, 2000) Diagnostic and StatisticalManual of Mental Disorders, Fourth Edition, Text Revision (DSM-IV-TR), defines ASD as a group of disorders that include autistic disorder, pervasive developmental disorder not otherwise specified (PDD-NOS), and Asperger's Disorder. The core deficits associated with an ASD are impairment in social interaction and communication, as well as the presence of unusual behaviors and/or interests (Al-Oran \& Al-Sagarat, 2016). The symptoms and characteristics can manifest themselves in a wide variety of combinations from mild to severe. Parents of children with autism should have great effort to seek knowledge and increase their understanding of autism in order to make informed choices for treatment which is costly.

Autism is profound developmental disorder with potentially risk effects on the entire family. Greeff \& Walt (2010)noted the presence of an autistic child in the family may have adverse effects on various domains of family life, including the marital relationship, sibling relationships and adjustment, family socialization practices, as well as normal family routines.

Individual with autism was high-risk for experiencing emotional dysregulation because it is directly related to the neurological basis of autism(Green, 2013).Sensory processing in autism play a major role in adaptation. Children with autism are often hypersensitive and/or hyposensitive to environmental stimulation. These caused child failureto regulate their emotion. Because of the severity of the disorder, many families seem consistently distressed and anxious about aspects of everyday life. Family member may be embarrassed if the child conduct inappropriate behavior typically associated with autism in public.

Family of an autistic child has a wrenching diagnosis story to tell because they face the horrible time when they learned unpredictable period that their autistic child might never speak, might never make friends, might never learn to be independent, might never learn to regulate their emotion. Caring for an autistic child demand much attention so parents do not have much personal time. Parents also blame themselves caused by their unfair treating to share attention and to spend the time withsibling while caregiver function focus on handling their child associated with autism behavior.

However, other families with a child with autism have managed to overcome the constant challenges and trials of autism. Families struggle to come to terms with their child's diagnosis and to adjust having a child with special needs in their home. Yumpi-R (2016) noted that parents provided vehicle for children to regulate emotion, such as appropriate voice to make instruction, massaged the body, food diet of CFGFSF (Casein Free, Gluten Free and Sugar Free), extinction, identified of stimulus which triggered of disregulation emotion and gave information of confining behavior. 
.The findings of this research could help better understand in describing emotional disregulation which is related to the neurological basis of autism, while others relate to characteristics of environments and social demands.

\section{SPIRITUALITY AND HUMAN NATURE IN ISLAMIC VIEW}

Religions, in general, aim to provide to the believers feasible ways to achieve happiness and have a comfortable life. Religion can provide answers to the wisdom behind the difficultsituations and past tragedy events, which can alleviatestress symptoms(Lamoshi, 2015). People with spiritual beliefs can benefit from their faiths and prayers in different ways; such as having a strong sense of peace, exercising their inner strengths and capabilities to cope with challenges, and improving their psychological status and quality of life. Furthermore, through prayer and rituals, people are able to feel connected to God and other believers from which they can derive the consolation and determination they need to handle the physical and psychological illness. Religion can encourage their followers to look at the world in an optimistic way, forget the past painful moments and enjoy their life.

According to Islam, worship is an act which everything a human being does with the pure intention of pleasing God. The mission of Prophet Muhammad encompassed not only spiritual and religious teachings, but also included guidance for such things as social reform, economics, politics, warfare and family life (Marzband, Hosseini \& Hamzehgardeshi, 2016).

In recent years, research has shown that religious commitment and spirituality are associated with many positive outcomes to improved ability to cope with parenting stress, reduced incidence of depression and anxiety. Spirituality and human nature become important issue to understand when working with Muslim. Islam is a religion that provides guidance about how to live, gives guidance to societal and serves as the vehicle how to increase self responsibility and relationships with family. The Qur'an and Sunnah's are the sources of the guidelines for Muslims. Islam, through the Qur'an provides the code of his or her behavior and answers the question of humankind's existence(Marzband et al., 2016). Islam's view of both the nature of the human being and the purpose of life are extremely positive. Worship is highly encouraged by Islamic principles because people can have an uncontaminated mind from past painful moments and no worries about the future. Cleaning the thoughts and souls, people would be able to see the beauty of life.

\section{BENEFICIAL RESILIENCES FROM THE ISLAMIC FAITH}

Pargament \& Raiya, (2007) stated that people draw on religious solutions to problems is triggered by particular situations, especially thosesituations that push the individual beyond his or her everyday understandingsand limited personal and social resources. Religion is considered as a protective factor for life stressors and is also protective against negative health outcomes(Salgado, 2014; Kulis, Hodge, Ayers, Brown, \& Marsiglia, 2012). There are several significant protective factor from the Islamic faith that can be incorporated into the resilience process. Followingthe concept family resilience, the use of coping strategies and family belief systems would be identified. The process would involve an evaluation and modification of perspective, followed bymodification of core beliefs and assumptions. A family with a child with autism may have burden that become negative thoughts such as "Why is this happening tome?" When understanding that their own child with autism as the purpose of trials and 
tribulations from Allah,family should accept sincerely. This family become resilience when family alter unproductive core-belief to assumptions which is taken from Allah said, such as: Do the people think that they will be left to say. We believe and they will not be tried". (Qur'an, 29: 1).

Salah (prayer) is a very important pillar of the Islamic faith. According to Islamic traditions, prayers help the believers remember God and protect them, as illustrated by the following verse from Qur'an: " Recite that which has been revealed to you of the Book and keep up prayer; surely prayer keeps one away from indecency and evil, and certainly the remembrance of Allah is the greatest, and Allah knows what you do." (Qur'an, 29:45). Islamic prayers also include ritual and supplication prayers.Henry(2013) stated Islamic prayers can produce spiritual energy that has the potential to heal and transform the person who prays. Many theorists argued that prayers in general could generate such energy. For example,James noted that prayers might fill people with spiritual energy that could influence them both psychologically and physiologically. Greef \& Joubert stated spiritual beliefs, practices, and support of a faith community can facilitate coping, adaptation, and resilience (Walsh, 2012a). Abundant research documents the powerful influence of spiritual beliefs andpractices for wellbeing, recovery, and resilience(Walsh, 2012b). This finding suggested that persistent prayers might yield a magnificent energy that could be very beneficial toresilience. Al-Owasi emphasizes that Holy Quran encourages Muslims to feel security, safety, peace, relaxation, tranquility, comfort, connection, sympathy, contentment, and reliance on Allah (SWT) and plants in the individual optimism and confidence in the Creator as also in the self, and the sense to avoid everything that is not beneficial to the self(Al-Thani, 2012).This will encourage the family to feed themselves with good inputs through the words and actions that would help others, and can in turn lead to healthy feelings, which can evolve a insight state of mind and fruitful thoughts.

Most important, exploring how families of child with ASD were building resilience thatwere derived from their perspective. What meaningful Islamic-valuescomposed family resilience are essential to identify in order to gain more complete understanding about experience of familywith autism child. In this article, I report the findings of a research study of family with autism child that contributes to the understanding about family resilience.

\section{METHOD}

The study aim was to understand how family with autism child experience could be resilient. How Islamic value constructs belief system that promote family resilience in family with autism child so family would be expected to better manage stress, have positive beliefs about their child with autism, be able to solve unpredictable problems that were caused by unusual behavior of their autism child.

The descriptive approach to case study was selected. Data was collected from many sources, such as in depth interview, observation and documentation. This study used purposive sample of family through criterion-based and convenience sampling strategy. Before the study commenced, the researcher obtain approval from early childhood education, Cahaya Nurani Islamic School which provided class for special need children. The participants who have been available by Cahaya Nurani Islamic School were families with autism child. Once a potential participant was identified, further information was sent about the study. A consent form was 
signed, and the family was requested to consider how they would like to participate. The researcher compiled parental interviews. The interviews took place in the family's home. The purpose for this was to gather data as close to the natural phenomena as possible. In this study, the opportunity to observe the child was important because the observation result could support the data. Parents were present when the researcher observed their autis child. After the interviews and observation, prior to formal analysis, the parents were given the opportunity to review the transcript of their own interviews as well as their children observation to add, alter, or delete information from the transcripts.

Data was analyzed using thematic methods to discover the nature and implications of the experiences of the participants. The researcher assessed the data which required reading the transcripts several times to discover an emphasis on commonality and emerging themes.

\section{INTRODUCTION OF PARTICIPANTS}

A family with autism child were involved in this study. The participants were assured of their anonymity. The participants were enthusiastic about sharing their lived experiences for the purpose of this case study. They told the stories of their experiences with candor and honesty. Ismed is an six-year-old with autism. Ismed attended the Sentra Anak Kebutuhan Khusus, the class for children with various special needs designations, Cahaya Nurani Islamic School where the researcher is the consultant for the special education and parenting program for early childhood development. Ismed was officially diagnosed with autism at the age of three and was therefore eligible to participate in the program as one of the designated children. Ismed has a high functioning form of autism. He has expressive and receptive speech and functions well in an inclusive classroom with the assistance of a shadow teacher. Sani is four years old and attends the same school as Ismed. Sani attends in regular class. Deby is the mother of Ismed and Sani.

As a consultant, the researcher has an opportunity to observe Deby several years. The researcher has made several observations of the outstanding parenting characteristics that she exhibits. The researcher believes Deby is an exemplary model for parenting a child with autism. The researcher deems her to be the pillar in this family. Her perseverance and dedication has inspired the researcher to conduct this case study and try to discover which attributes contribute to their families success. The interviews with Deby were very extensive and offered valued information and insight into the lives of the participants.Salim is the father of Ismed and Sani. The researcher has come to know her well than Salim because Deby is the parent who has transported the children to and from school and has attended parenting program and personal program planning meetings. Nevertheless, the dynamics of their family life would not be completely represented without the father's perception and input

\section{FINDING}

\subsection{Wonderful Purpose Behind Adversity and Stress}

In this theme parents describe how a family with autism child dealt experience serious psychological distress. When they first heard the formal diagnosis from a team of professionals at the Cahaya Nurani that their child autism was suspected, their reaction's were grieve, disappointment, disbelief and also resentment. Deby and Salim recalls their feeling: 


\begin{abstract}
"When Ismed was 2 years, I was concerned....., he was different with other kids with the same age. He could not speak. He performed typical behavior differently with other child. We consulted the doctor about the strange his behavior. According to the doctor, my child was indicated from his behavior as autism. I was distrusful about my child's behavior cause I have browsed autism characteristics...... and I recognized that his typical behavior was appropriate with these characteristic. You know, I worry about the development and my child's future. I felt confusion, denial, and shock. I cried, and cried, and cried" (Deby)
\end{abstract}

Salim, Ismed's father also stressed facing the child diagnosed which confirm autism spectrum. He refused the diagnosis and he considered the delayed development of his child. He convinced himself that Ismed would take time longer in development than normal child. $\mathrm{He}$ made effort to overcome what happened in his child by using traditional approach which was recognized as myth for child with delay speech. Salim told his validated experience:

"I tried to heal my child in traditional way such as hitting Ismed's mouth by using betel leaf, massage Ismed's tongue with gold ring every Friday noon. Ismed refused and cried....... My wife was not sure about this because she thinks it was myth so she asked me to stop...but I ignore her. I became conscious of my son's autism since my colleague at work told me that Ismed's behavior was similar to his child behavior that was diagnosed autism. Ismed did't make eye's contact when he tried to make interaction with me. He acted, as if there were no body around him. My friend suggested to Cahaya Nurani, the Islamic inclusion school for early childhood education. The assessment from professional team at Cahaya Nurani reported that Ismed was suspected" (Salim)

Salim and Deby clarified that although the diagnosis seemed tragic and overwhelming, they had the fortitude to do what was needed to improve the life of their son. Their first step in recovering from their grief was acceptance and understanding. Then, they used Islamic value to find meaningful life behind the autism diagnose of their child. Salim told how his belief system worked for promoting his family become acceptance and understanding:

"I realized that my lovely son was autistic. ....but...You know that I could not accept the diagnose. Then, I know what I did could make me stress. My wife cried, and cried, and cried....oh...I was confused. I then remembered that I was just a human. This was not something I could have avoided. I knew this was the plan that Allah had prepared for my family. I told Deby that Allah knew we were strong enough to handle this trial. I asked her to stop crying and to find the best solution for Ismed. "(Salim)

"Autism, this word shot through my ears. I felt confusion, denial, shoc, pain, heartbreak, and sadness. I cried, and cried, and cried. I then surrendered my sadness to Allah, ... Oh.... knew this was not easy. It was then that I felt the need to 
pray and pray until I find strength in my self. Alhamdulilah, we had high motivation for autism intervention in order to develop Ismed better" (Deby)

Although this is a study of strength and resilience, one cannot be perceived as resilient until first faced with adversity. It was important for Salim and Deby to identify the elements that enabled them to cope effectively and emerge from crisis or distress through strength and fortitude. Deby and Salim were able to withstand adversity of these stressors and rebound successfully because of their belief in coping strategy. Greater insight may be gained from their limited resource to bring their autism child like another child with normal development. The beliefs which emerged as family strength for coping strategy were: a) the family was confident that Allah gives this test because they had the capacity to handle this trial; b) they surrendered to Allah about their burden which related with autism child; c) they knew that this was the plan that Allah had the best purpose for them. These belief have brought family become acceptable to cope adversity.

\subsection{Gratitude to small successes}

Autism was complex disability that affects developmental child. Most parents initially teeter between hope and despair to anticipate the unpredictable development. Assisting children with autism requires flexibility. This can be a formidable task but Salim and Deby have been instrumental facilitators. Despite Ismed could reach little step in development, Salim and Deby demonstrated appreciation. This theme describe how established patterns of family functioning which refers to the internal strengths and durability of the family unit. Gratituted to small successes could promote significantly to family functioning. Below Deby and Salim share their grateful experience.

"Ismed has not talked yet until he was 4 years old. He jabbered,.... shouted.... Subahanallah, I was happy when he called me "mommy"... Unbelievable....mommy was the first word from Ismed. I grabed him....I was touched. I praised Allah. Really... I have been waiting for this moment. (Deby)

Alhamdulilah, I was thankful when Ismed could ride a bike. Some kids do learn easily, progress academically, and become independent. I worked very hard with careful planning to increase Ismed's ability. when he accomplishes some minor task, I appreciate him. Salim

The researcher could display data which was provided from observation. In the following example:

Ismed rode his bcycle in the yard in front of his house. Salim, his father, began to hold him and bicycle to keep them balance. Ismed pedaled excitedly. His father then let him go to ride by himself. Salim say: "You can ride, Ismed. Come on,....keep pedaling....". Salim grabbed the bicycle from behind when Ismed was imbalanced. Ismed looked hesitate to pedal again. "Ready Ismed? Okay say, 'Bismillah . . come on, 'Bismillah" (observation, augst, 16) 
Through observation and interview it would appear that Deby and Salim demonstrated gratitude which encouraged them to attain strength and a sense of hope or optimism for helping Ismed accomplishment his task.

\subsection{Focusing on hereafter}

.Parents try to build their children the foundations of a successful future. Parents make great efforts for their children to grow up, to be well-rounded and well-adjusted adults who are capable of contributing to the society and starting a family of their own. Salim and Deby understand that Ismed needs individualized support and encouragement to succeed. His impairments in communication and social skills increases the difficulties how he has been adjusting to life. Salim and Deby realized that they have limited resources about the practical aspects of raising their autism child. This theme emerges as an illustration how the family could maintain a positive outlook, hope, commitment and patience to adapt to having an autistic child. Deby and Salim recognized the importance of preparing children for the Hereafter, and the obligation of protecting them from the hellfire. Focusing on hereafter was considered as a positive outlook so parents could display optimistic in their parental role. This theme describe Hereafter becomes the main concern and provides valuable hope, comfort and encouragement.

"I am his mom, I know well my child, my top priority as parents should be to nurture and strengthen spirituality. I teach him sholat and read Qur'an. I believe the Paradise that Allah will give to all His servants. Now, Allah give us to care Ismed.... May Allah grant us to His Paradise"

"I told to my wife not to worry about his future. You are his mother, you are madrasah for him so don't worry if he can't go to school that caused by his impairment. The importance is teaching him for sincere obedience to Allah. And, the importance is teaching him how respect to parents. No matter what he is, Allah look after him" Salim

\subsection{Having a support system for powerful energy}

Did this family receive support from their surroundings? Who supported this family? Supports from family member could emerge as a powerful optimistic energy to strengthen continue on their life with daily challenges and adversity. The role of supports to the family significantly contributes to the parent's reduction in stress because the process of coming to terms with autism diagnosis could make them painful, encompassing feelings such as shame, guilt and self-pity. This theme describes how family members can be encouraged to balance with assistance from community, extended family, and friends. There were numerous examples in the interviews of support.

My father (Ismed's grandfather) reminded me not to waste time for regretting because Allah permitted this trial in our life. My father suggested to accept the diagnosis. My extended family supported me to do what professional team recommended for Ismed. (Salim)

"I was not sure that I could overcome this burdenwithout my family and friends. My husband gave me a shoulder to cry on and constantly reminded me to regard that 
Proceeding ICOGISS 2019

Page 105-118. ISBN: 978-602-6 988-75-1

Web Jurnal Online: jurnal.unmuhjember.ac.id

By: Festa Yumpi Rahmanawati

Building Family Resilience: A Case Study In A Muslim Family With Autism Child

our son as gifts from Allah. We should be patience and patience because we want blessings from Allah"(Deby)

Deby received support from Ismed's teacher for successfully meet Ismed's needs "The teachers make efforts to ensure that Ismed participate in individual program. Two weeks ago Ismed's math ability decreased. I discussed how to solve the problem with his teacher"

This family also joined support group and parenting skill program which have been held by school where Ismed attended. They listened and learned about other parent's experience in facing autism child.

"I learned from other parents in support group about autism diet and handling emotional problem. I learned a lot from them. And I was strong enough. In this group I learned the power of prayer beside the skill for autism intervention child. I could discuss my fears in this group. Then, I realized that hope and love that I have make me stronger. (Deby).

This family have social support from surrounding, such as teacher, other parents, extended families and communities. The existence of support group and parenting skills program can be great sources of information about what services are available for parents. One of the strong pillars in resilience is having positive relationships or feeling connected to others.

The overall stories revealed from this study tell us about a shift from deficits towards strengths. The process would then involve core beliefs and assumptions from Islamic value. Hence, the process contributed to healthy family functioning, and therefore increased resilience.

\section{DISCUSSION}

This study aim to explores how families of children with ASD were build resiliences that were provided from families of children with ASD point of view in using Islamic values. To meet this aim, a case study of family with autism child was conducted. After the analysis was performed, four themes come in to view.

The overall results demonstrated the process of a shift from deficits towards strengths. This study identified Islamic values which built family resilience. Autism is a severely debilitating developmental disorder with potentially harmful effects on the entire family. Family members reported their perspective of Islamic values that promoted them to be resilience eventhough they faced the challenges of their autistic child.

The first theme is "Wonderful Purpose Behind Adversity and Stress". It reflects how a family overcome stress that was caused by a formal diagnosis that their child had autism. Parents reported that they believe Allah had a reason behind the burden which is related to the autism child. This belief become resources of family that enable them to accept and understand. The reflection of acceptance and understanding could be derived from the Qur'an (64:11). The family said that what made their work so valuable was that they themselves had suffered from afflictions and experienced the positive effect of prayers. The family have the hope of earning reward from Allah for submitting to Him and the events that He has planned. The Qur'analso 
affirms it by saying: "God is with those who patiently persevere" (Qur'an, 2:153) and "Be not sad, surely God is with us" (Qur'an, 9:40). In the family resilience context, supplications will give courage to withstand in a desperate situation when treatment of their autism child will not help to accomplish normal development. According to Walsh (2012a), the family resilience involves the potential for personal and relational transformation and growth that can be forged out of adversity. This family reveals confidence in overcoming problems dealing with their autism child. Bandura noted that confidence was considered as self efficacy which was defined the belief of an individual in performing an action. Parents' self-efficacy is important in coping with stress andbalancing emotions and in intellectual adaptation to the situations encountered in parenting (Bhagat \& Haque, 2015). Perceived self efficacy is an attribute that has assisted this family in developing a healthy adaptation when faced with the adversity of parenting a child with autism (Mierau, 2008). The capacity of the participants to believe in trial from Allah has been an immense advantage for them. Perceive self-efficacy emerged due to their belief that Allah knew that they have capacity to overcome the test. The following verse from the Qur'an shows how faith transforms and strengthens those who believe in test: "And We will surely test you with something of fear and hunger and a loss of wealth and lives and fruits, but give good tidings to the patient, who, when disaster strikes them, say: Indeed we belong to Allah, and indeed to Him we will return.?" (Qur'an 2: 155-156).

The theme "gratitude to small successes" is reflectingthe ability of family to gratitude which encouraged them to attain strength and a sense of hope or optimism. Gratitude is a positive feeling, whereby experience of gratitude as a pleasant emotion and will usually be followed by other positive emotion (Watkins, 2014). The family in this study expressed happiness in small accomplished task of their autism child by saying "Alhamdulilah" it means praise and thanks are to God. The family also showed appreciation, thankfulness, and a sense of wonder. The gratitude become crucial variable contributing to resilience and effective family functioning.Kumar \& Dixit (2014) show the study that significant positive correlation was found among gratitude and resilience. To be able to cope problem of autism child, family must have the competence of being able to strengthen the protective factors, minimize risks, and give a positive influence in the psychological development of children in the family context. One of the efforts to form a strong and positive person as a member of family is by strengthening the experience of gratitude. The gratitude is associated with ability of someone who grabs and understands the positive of everything and gives it to others.

Lau \& Cheng (2015) report the study that gratitude was related to the greater use of emotion-focused coping (positive reframing, acceptance, humour, emotional social support seeking, religious coping and psychological resources (caregiving competence and social support). Psychological resources and emotion-focused coping in turn explained the association between gratitude and lower levels of psychological distress (caregiving burden and depressive symptoms)

Gratitude is the fundamental aspects of Islam, it is classified in to two; one is gratitude to Allah and other is gratituted to creation of Allah. Muslim expressing in any happiness moment by saying. The type of gratitude is the recitation of Qur'an. The family with autism child in this study have gratitude as faith that recite in Qur'an:"And (remember) when your Lord proclaimed, 'If you are grateful, I will surely increase you (in favor); but if you deny, indeed, My punishment is severe." (Qur'an 14: 7). Samuels (2012) state that inner strengths or resources 
can serve as a foundation for building parent's resilience. These may include faith, flexibility, humor, communication skills, problem-solving skills, mutually supportive caring relationships, or the ability to identify and access outside resources and services when needed. This study support that gratitude is faith which have powerful effect on family resilience. Previous study conclude that gratitude was correlated with traits associated with positive emotional functioning, lower dysfunction, and positive social relationships(Amaro \& Miller, 2016; Listiyandini, 2018). Grateful people were less angry and hostile, depressed, and emotionally vulnerable, experienced positive emotions more frequently.

Focusing on hereafter is the theme to describe how the family could maintain a positive outlook, hope, commitment and patience to adapt to having an autistic child. When family concerns and worries of their autism child, they faced unseen future. If the Hereafter becomes the main concern, the family is likely to become content and determined. This entails the understanding that the Hereafter is for eternity and thus, something that must be given due attention(Hamdan, 2008). In focusing on the Hereafter, one prepares to meet Allah in the best state. In the end, the supreme goal for both parents and children is paradise. The family in this study have changed their dysfunctional core beliefs and assumptions about their autism child with more meaningful beliefs in order to positively affect emotion and behavior.

The theme "Having a support system for powerful energy" represents the importance network system that helped family with autism child to facedaily challenges and adversity. From the stories of the family, we could see that they received social support from their surroundings when they needed information about the best treatment and when they want to express their worry. The family have meaningful insight when the information content Islamic values, such as relying on Allah, trusting to prayer. One of the foundations of Islamic belief is the understanding that Allah is able to do all things and He runs all affairs. This is an aspect of tawheed (belief in the oneness of Allah) that specifies oneness in Allah's Lordship (Bensaid et al., 2014). From the case study, we learn about resilience of family with autism child. This can be accounted for by the fact that families with a developmentally disabled child generally possess a degree of resilience and adaptability. The interview and observation demonstrated the family's ability to bounce forward from a crisis situation by using faith deriveded from Islamic value. In the word of (Walsh, 2012a)ability in operating family function to adapt under challenging and adversity, including strong emotional bonds, effective patterns of communication, the use of coping strategies and family belief systems, especially those based on spiritual or religious value.

\section{CONCLUSIONS AND RECOMMENDATION}

This study supports a large body of research documents about faith and spiritual resources which have been found to be wellsprings for family resilience. More studies are highly needed to reveal the resilience of family with autism child. This study involves only one family affected by high function autism and is limited in that respect. It is important to note that a preconceived autism.category based on severity level. The diversity autism level might conceal different dynamic on how family build resilience by using Islamic values. The more aspects that are revealed, the more knowledge and understanding will be gained about family resilience. 
Proceeding ICOGISS 2019

Page 105-118. ISBN: 978-602-6 988-75-1

Web Jurnal Online: jurnal.unmuhjember.ac.id

By: Festa Yumpi Rahmanawati

Building Family Resilience: A Case Study In A Muslim Family With Autism Child

\section{REFERENCES}

Al-Oran, H. M., \& Al-Sagarat, A. Y. (2016). Parenting Stress of Children with Autistic Disorder. Open Access Library Journal, 3, 1-10. https://doi.org/10.4236/oalib.1102791

Al-Thani, A. S. (2012). An Islamic Modification of the Person-Centered Counseling Approach. QScience.com.

Amaro, L., \& Miller, K. (2016). Discussion of Care, Contribution, and Perceived (in) Gratitude in the Family Caregiver and Sibling Relationship. Personal Relationships, 23, 98-110. https://doi.org/10.1111/pere.12113

Bensaid, B., Machouche, T. S. ben, \& Grine, F. (2014). A Qur'anic Framework for Spiritual Intelligence. Religions, 5, 179-198. https://doi.org/10.3390/rel5010179

Bhagat, V., \& Haque, M. (2015). Parent's Self-Efficacy, Emotionality, and Intellectual Ability Impacting the Intervention of Autism Spectrum Disorders : a Review Proposed Model for Appraisal of Intervention. International Journal of Pharmacy and Pharmaceutical Sciences, 7(11), 7-12.

Greeff, A. P., \& Walt, K.-J. van der. (2010). Resilience in Families with an Autistic Child. Education and Training in Autism and Developmental Disabilities, 45(3), 347-355.

Green, L. (2013). The Well-Being of Siblings of Individuals with Autism. ISRN Neurology. https://doi.org/http://dx.doi.org/10.1155/2013/417194

Hamdan, A. (2008). Cognitive Restructuring: An Islamic Perspective. Journal OfMuslim Mental Health, 3, 99-116. https://doi.org/10.1080/15564900802035268

Hayes, S. A., \& Watson, S. L. (2013). The Impact of Parenting Stress : A Meta-analysis of Studies Comparing the Experience of Parenting Stress in Parents of Children With and Without Autism Spectrum Disorder. Journal Autism Development Disorder, 43, 629642. https://doi.org/10.1007/s10803-012-1604-y

Henry, H. M. (2013). Spiritual Energy of Islamic Prayers as a Catalyst for Psychotherapy. Journal of Religion and Health. https://doi.org/10.1007/s10943-013-9780-4

Kulis, S., Hodge, D. R., Ayers, S. L., Brown, E. F., \& Marsiglia, F. F. (2012). Spirituality and Religion: Intertwined Protective Factors for Substance Use among Urban American Indian Youth. The American Journal of Drug and Alcohol Abuse, 38(5), 444-449. https://doi.org/10.3109/00952990.2012.670338

Kumar, A., \& Dixit, V. (2014). Forgiveness, Gratitude and Resilience among Indian Youth. Indian Journal of Health and Wellbeing, 5(12), 1414-1419.

Lamoshi, A. Y. (2015). Religion as a Resilience Tool to Manage Stress in Adolescents: Islamic Approach. Global Journal of Human-Social Science: H Interdisciplinary, 15(3).

Lau, B. H.-P., \& Cheng, C. (2015). Gratitude and Coping among Familial Caregivers of Persons with Dementia. Aging \& Mental Health. https://doi.org/10.1080/13607863.2015.1114588

Listiyandini, R. A. (2018). The Influence of Gratitude on Psychological Resilience of Adolescence Living in Youth Social Care Institutions. Journal of Educational, Health and Community Psychology, 7(3), 197-208. 
Page 105-118. ISBN: 978-602-6 988-75-1

Web Jurnal Online: jurnal.unmuhjember.ac.id

By: Festa Yumpi Rahmanawati

Building Family Resilience: A Case Study In A Muslim Family With Autism Child

Marzband, R., Hosseini, S. H., \& Hamzehgardeshi, Z. (2016). A Concept Analysis of Spiritual Care Based on Islamic Sources. Religions, 7(61), 1-11. https://doi.org/10.3390/rel7060061

Mierau, L. J. (2008). Emerging Resilience in a Family Family Affected by Autism. University of Saskatchewan Saskatoon.

Pargament, K. I., \& Raiya, H. A. (2007). A Decade of Research on the Psychology of Religion and Coping. Psyke \& Logos, 28, 742-766.

Salgado, A. C. (2014). Review of Empirical Studies on Impact of Religion, Religiosity and Spirituality as Protective Pactors. Propósitos y Representaciones, 2(1), 121-159. https://doi.org/dx.doi.org/10.20511/pyr2014.v2n1.55

Sixbey, M. T. (2005). Development of the Family Resilience Assessment Scale to Identify Family Resilience Constructs.

Walsh, F. (2012a). Family Resilience, Strengths Forged through Adversity. In Normal Family Processes (4th ed., pp. 399-427). New York: Guilford Press.

Walsh, F. (2012b). The Spiritual Dimension of Family Life. In Normal Family Processes (4th ed., pp. 347-372). New york: Guilford Press.

Watkins, P. C. (2014). Gratitude and the Good Life. Dordrecht Heidelberg: Springer Science Business Media.

Yumpi-R, F. (2016). Peran Orangtua pada Regulasi Emosi Anak Autis (The Role of Parent to Emotional Regulation of Autism Child). Insight, 12(1), 39-56.

Zanariah, R. A., \& Shah, I. (2015). Measuring Islamic Spiritual Intelligence. Procedia Economics and Finance, 31(15), 134-139. https://doi.org/10.1016/S22125671(15)01140-5 